\title{
Opinião
}

\section{O USO DAS NOVAS TECNOLOGIAS DE COMUNICAÇÃO NO ENSINO SUPERIOR}

\author{
Sidney Medeiros de Oliveira (1) \\ Weilher Feitosa de Melo (2) \\ Solânia Eugênio Santos Maia (3) \\ Adelmar de Sousa Marinho Neto (4)
}

\begin{abstract}
Resumo
Nas sociedades contemporâneas não mais se pode fugir ao uso de tecnologias para a solução dos problemas cotidianos. Essas mesmas tecnologias são utilizadas como meio de aquisições e atualizações de informações na maioria dos setores da sociedade. Essas novas tecnologias facilitam e, agilizam a vida do ser humano. Tomando como exemplos os setores bancários, de informática, de televisão, de telefonia, etc., dá para se ter uma idéia de como essas atualizações se fazem necessárias no nosso dia-a-dia. O presente estudo, visa apresentar elementos que esclareçam como as novas tecnologias estão influenciando as metodologias e, as novas formas didáticas, utilizadas no ensino superior. Também, como que essas inovações influenciam no aprendizado dos alunos, procurando discutir a eficácia desses novos métodos na relação ensino-aprendizagem.
\end{abstract}

Palavras-chave: Tecnologias; metodologias; ensino superior.

\section{Introdução/Desenvolvimento}

No mundo antigo as informações, assim como os conhecimentos, eram repassados de forma verbal. Na idade média a evolução da informação se deu através dos monges escribas, 
assim como, no Renascimento aconteceu através da palavra impressa (SANVITO, 2001). Nos dias de hoje a informação e o conhecimento são difundidos através de televisão, telefones celulares, computador, internet e outros tipos de tecnologias.

Os tempos modernos trouxeram avanços tecnológicos em vários setores da nossa vida e o ser humano tem a incumbência de estar frequentemente se adaptando a essas novidades. Hoje são notórias as modificações alavancadas pelas novas tecnologias que a cada momento se atualizam e nos mostram mais facilidades para o nosso dia-a-dia. Algumas dessas facilidades podem ser observadas nos setores automobilístico, bancário, de telefonia, da educação, este último, que será tema deste trabalho, traz muitas novidades, as quais, os profissionais da área podem lançar mão. Para citar alguns exemplos, temos: $\mathrm{O}$ data-show, os novos programas de telefones celulares, os programas de e-mail, os novos sistemas de televisão, etc.

Essas inovações têm dois aspectos a serem considerados: As vantagens e desvantagens. O primeiro aspecto diz respeito à facilidade de aquisição e utilização das novas tecnologias no nosso cotidiano. Na indústria automobilística a introdução do câmbio eletrônico pode ser um bom exemplo dessas novidades. Outro exemplo são os famosos tablets, pequenos computadores em forma de bandeja que são a sensação da atualidade. Não podemos deixar de falar dos televisores “3D” que trazem as imagens para perto do expectador.

Todas essas novidades facilitam a vida das pessoas que podem ter acesso a esses equipamentos. Porém, há de se considerar que, em contrapartida, quando essas tecnologias falham ou apresentam algum problema, aparecem as dificuldades. As pessoas estão se acostumando com as novas tecnologias e estão ficando refém das mesmas. Quando ocorre qualquer imprevisto no funcionamento desses equipamentos tecnológicos, aparecem as dificuldades.

Segundo Pimenta (2002,) a educação na universidade pressupõe preparar os jovens para alcançarem um nível elevado em termos de civilização, de riqueza, com consciência dos seus problemas, a fim de que aí atuem. Isso requer uma preparação científica, técnica, social e de valores. E acrescenta:

(...) a finalidade da educação escolar na sociedade tecnológica, multimídia e globalizada, é possibilitar que os alunos trabalhem os conhecimentos científicos e tecnológicos, desenvolvendo habilidades para operá-los, revê-los e reconstruí-los com sabedoria. O que implica analisá-los, confrontá-los, contextualizá-los. Para isso, há que articulá-los em totalidades, que permitam aos alunos ir construindo a noção de cidadania mundial. (p.81) 
O fenômeno da globalização tem facilitado que a informação chegue de forma muito rápida em qualquer lugar do planeta. Até mesmo para facilitar o ensino-aprendizagem, as novas tecnologias de educação inseridas neste contexto, são muito utilizadas pelos docentes, sendo que, alguns até temem erroneamente que, com passar do tempo, o professor perca as suas funções de facilitador, para ser apenas um orientador e administrador dos recursos tecnológicos. Pimenta (2002, p. 99) compreende este fato da seguinte maneira, “(...) o trabalho do docente aí é o de monitorar o programa, ajudando e assessorando os alunos na execução das tarefas. (...) Essa política altera a identidade do professor para a de um monitor”.

Observa-se uma tendência a, cada vez mais, se diminuir as aulas expositivas, dando lugar ao uso de um sistema tecnológico, que vá gradativamente sendo assimilado na rotina da sala de aula. Este possibilitando uma efetiva troca, onde o professor deixa de ser alguém que apenas fala e, começa a ouvir mais e propor mais ações interativas, construindo conjuntamente o saber. Sobre esse assunto, Brito e Purificação (2006) relatam que, para que haja uma concretização enquanto projeto de mudança, a Universidade não pode perder a capacidade de investigar, de questionar, de incomodar ou, de criar soluções para esses novos desafios tecnológicos ou social. Isso representa uma necessidade de urgente adoção de um pluralismo de idéias, acompanhado de solidariedade, ética e excelência profissional.

Os docentes, pois, têm que reconhecer, a partir da consolidação dos novos recursos didáticos que, as exigências e os critérios para se exercer a docência aumentaram. E a tendência é aumentar ainda mais. Com isso, além da necessidade de uma atualização mais constante, em termos dos avanços tecnológicos, torna-se imprescindível, o aprofundamento por meio do conhecimento advindo da pesquisa, relacionada às novas tecnologias didáticas possíveis.

Neste sentido, acreditamos ser necessário discutir o uso das novas tecnologias e sua aplicação no ensino superior, através de uma revisão da literatura especializada. Para isso, torna-se também importante, conhecer as diversas opiniões dos autores consultados sobre a temática, bem como conhecer aspectos relacionados com aplicações bem sucedidas das novas tecnologias, aplicadas à educação superior.

\section{As ferramentas tecnológicas e o sistema educativo universitário}

Em geral, o sistema educativo é um processo humanista em sua essência. Isto é, as pessoas tendem a se ajudarem no processo de construção do conhecimento. O professor, até 
então tem atuado de uma forma ativa, ensinando e orientando os aprendizes, de modo a satisfazer as necessidades sociais. A apropriação do conhecimento, acontece, tanto á partir do pensamento funcional, de acordo com a percepção de cada um num contexto, da tecnologia utilizada para facilitar e, do conviver social, isto é, da experiência de vida. Uma sociedade que adere à educação é uma sociedade que, em geral, pensa e analisa os fatos, sem julgá-los prematuramente, ocasionando assim dificuldades sociais. $\mathrm{Na}$ universidade não é muito diferente e, como cita Masetto (1998, p.23) “Não será a mesma coisa a aprendizagem com ou sem tecnologia".

Em termos de aprendizagem, a universidade está cada vez mais evoluída. Novos conhecimentos são gerados a cada instante, tornando o ensino cada vez mais especializado e fragmentado. Novas formas de apropriação do conhecimento são necessárias, de forma que, não é mais o professor que ensina, que domina o conhecimento, mas o aluno é quem aprende.

Este novo paradigma dá ao aluno mais responsabilidade, um papel mais ativo no seu processo de busca do conhecimento. Novas competências passam a serem necessárias como valores e atitudes, complementando a aquisição dos novos conhecimentos, bem como facilitando a interação social, promotora de novos conhecimentos. Neste sentido, o papel do professor, torna-se cada vez mais descentralizado em si, e portanto há uma tendência ao uso de soluções inovadoras para motivar a assistência para as explanações. Sobre esse aspecto, Masetto (1998, p.18), nos informa que “(...) o papel de transmissor de conhecimento, função desempenhada até quase os dias de hoje, está superado pela própria tecnologia existente".

Neste contexto, cada produção dos alunos, tende a motivar o professor a atualizar seus estudos, ajudando a incrementar a sua didática. Rompe-se com o modelo arcaico de ensino, e ajuda-se os alunos, não a conhecer o assunto por meio da memorização dos mesmos, mas de uma compreensão, onde o aluno atua também como autor desse conhecimento através de interações ativas.

A evolução acelerada das tecnologias de comunicação e informação, tem impulsionado, sobremaneira, as formas de convivência social e, de processos de trabalho das pessoas. Nesse ponto, as universidades enquanto produtoras de novos conhecimentos, precisam fazer um esforço maior, para unir o ensino tradicional com as tecnologias disponíveis, de modo a manter saudável as discussões e motivação acadêmicas. Isso significa, tornar essas ferramentas tecnológicas, um aliado, um recurso para agilizar a aprendizagem. Neste sentido, torna-se necessário que o professor consiga facilitar que o aluno aprenda a agir em sociedade, conviver eticamente e ainda desafie-se no meio acadêmico, ajudando na sua motivação para aprender mais e mais. 
O que pode ser constatado no meio universitário é de que os indivíduos já entram na sala de aula desejosos por novidades e, motivados a usarem novas ferramentas de comunicação. Isso porque fora do mundo acadêmico, já não há mais diferenciação da tecnologia com o trabalho. Portanto, demandam por aulas que atenda suas necessidades reais, advindas do seu cotidiano. Masetto (1998) nos leva a pensar a respeito quando declara que a tecnologia é importante, mas, principalmente porque nos irá forçar a fazer coisas novas, e não porque permitirá que façamos melhor, as coisas velhas.

Para haver a utilização de toda e qualquer ferramenta tecnológica, é necessário compreensão antes, da finalidade desta utilização. O ensino, à partir das novas tecnologias educacionais, pretende muito mais do que um preparo dos alunos, do ponto de vista de saber manusear. Pretende também abrir possibilidades de diversificar o método, para se alcançar os objetivos educacionais. A questão posta, pois, não está no que se aprende, mas no como se aprende.

A educação hoje, não consegue mais prescindir da informação. Esta está associada de maneira simbiótica ao processo de ensino-aprendizagem e, já faz parte do cotidiano educacional.

Nos indagamos pois, o que a convergência digital tem mudado em nossa sociedade e consequentemente em nossas salas de aula?

Masetto (1998) nos orienta que, cada vez mais, surgem transformações produzidas pela introdução da tecnologia no ensino, que geram impacto e influenciam no futuro profissional. Hoje, o mercado de trabalho exige um conhecimento prévio das ferramentas tecnológicas, principalmente as da área da informática. Educadores universitários, já facilitam suas atividades de planejamento, apresentação de aulas-expositivas através de diversos e modernos recursos multimídia, data-show, computador, e televisão.

No Brasil, Sem supervisão, os computadores nas escolas brasileiras mais distraem do que ensinam. Pesquisa publicada na Revista Veja (2008), demonstrou que em 38\% das escolas públicas de Ensino Básico já têm PCs instalados; Ainda que, sem a supervisão dos professores, as crianças perdem tempo em frente ao computador com atividades sem nenhuma relevância para o ensino. Isso é, com jogos e bate-papos virtuais; E que, os professores não são preparados para o uso pedagógico do computador. Não há treinamento suficiente para os mesmos.

Explora-se o que há de mais positivo com a presença das novas tecnologias: a facilidade de comunicar conteúdos, que dá ao espectador facilidade e liberdade para produzir e veicular seus trabalhos escritos, ensaios, resenhas, pesquisas. 
Embora, hajam educadores que são resistentes à utilização de novos equipamentos para ministrar suas aulas. Os EAD (Ensino à distância) são outro aspecto do uso de tecnologias na educação. Algumas Universidades já utilizam desse instrumento para aplicar seus cursos de graduação e extensão. No Brasil esse tipo de mecanismo foi introduzido há poucos anos e ainda provoca desconfiança por parte da população, pois muitos ainda não têm acesso à internet, e, com isso, preferem o modelo tradicional de educação.

Outras formas de interagir com os alunos e disseminar o conhecimento é através da utilização de Blogs, Sites, E-mails, Comunidades virtuais, Salas de bate-papo, dentre outras.

As ferramentas tecnológicas tem demonstrado ser muito eficientes e atrativas, facilitando a fixação do conhecimento, uma vez que, promovem uma comunicação de forma rápida, aguçando mais de um sentido, ao mesmo tempo: visão e audição.

Segundo Perrenoud (2000, p.139),

a verdadeira incógnita é saber se os professores irão apossar-se das tecnologias como um auxílio ao ensino, para dar somente aulas bem ilustradas por apresentações multimídia, ou para mudar de paradigma e concentrar-se na criação, na gestão e na regulação de situações de aprendizagem.

Pode-se pensar que, um mundo cada vez mais tecnológico, tende a ser um mundo menos humano, uma vez que, em muitos casos, o homem vem sendo substituído pelas máquinas e, a experiência profissional pode vir a se resumir na experiência em operar algum tipo de equipamento eletrônico. Neste sentido, Assman (1998) nos comunica que, o ser humano vive conectado a uma rede de informações, direcionadas para o desenvolvimento do intelecto e, facilitadas pelas tecnologias, que por sua vez, facilitam a produção de novos conhecimentos.

Atualmente, os profissionais de todas as áreas, procuram se adaptar às novas tecnologias, procurando utilizá-las de forma a obter um melhor desempenho na sua atividade profissional. Na educação, os docentes precisam estar sintonizados com as novidades e, com as novas possibilidades de utilização destas, no processo ensino-aprendizagem, até como diferencial competitivo.

Diante do exposto, fica demonstrada a crescente a necessidade de se discutir as aplicações das novas tecnologias na educação superior. 


\section{Resultados}

Observou-se que na docência, os professores podem utilizar as novidades tecnológicas para, incentivar e facilitar os alunos a criarem, bem como a exporem suas próprias idéias sobre o conteúdo apresentado. Dessa forma, promovem a interação entre o conteúdo apresentado, o professor e o aluno.

O uso de metodologias adequadas à modernidade, torna o ensino mais agradável e, o aluno poderá, com a mediação do educador, ser capaz de apresentar soluções, cada vez mais criativas, para os problemas cotidianos. Dentro dessa lógica, nos orienta Fantin (2005, p.1), "se as pessoas estão sendo educadas por imagens e sons [...] pelos meios eletrônicos [...] como um dos protagonistas do processo culturais e educativos, a escola precisa pensar tais potencialidades".

Entretanto, o docente não pode apenas chegar à sala e por um vídeo para os alunos assistirem, sem contextualizar o assunto. Essa atitude resultaria em perda de tempo, pois é necessário questionar, debater e levar ao aluno pensar sobre o que está acontecendo e o que se quer comunicar. Deve-se também levar em consideração que, o professor não é dono absoluto do conhecimento. Há uma troca de saberes na construção do conhecimento, de forma conjunta. O professor necessita estar em constante atualização, para que possa dar conta das novidades em termos de conhecimentos, habilidades e das novas tecnologias disponíveis.

Masetto (1998) coloca que, apesar de alguns docentes procurarem estar sintonizados com as habilidades e conhecimentos requeridos no mundo acadêmico, precisam também conseguirem transmitir os conteúdos de maneira eficaz. De forma a tornar facilitada a assimilação por parte dos alunos. Em geral, o domínio de alguns recursos tecnológicos facilitariam esse processo. "Hoje, as mais de cem técnicas de aula existentes e aplicadas, juntam-se as novas tecnologias relacionadas com a informática e a telemática: o computador no processo de ensino-aprendizagem, na pesquisa, a Internet, o data-show, a videoconferência, o e-mail, etc" (p.23).

É certo que as universidades estão buscando adaptar-se ao novo contexto tecnológico, pois não têm como fugir disso. As que resistem, estarão na eminência de perderem educadores e acadêmicos e, sua tendência é fecharem as portas, porque hoje para qualquer profissão, exige-se o conhecimento de ferramentas tecnológicas, de forma a não ser mais um excluído do mercado de trabalho. 
O professor, neste contexto, também precisa se adaptar, ministrando aulas com criativas, dividindo com os alunos a responsabilidade na geração de novos conhecimentos. Como nos relata Pimenta (2002, p.82) “(....) para saber ensinar, não bastam à experiência e os conhecimentos específicos, mas se fazem necessários os saberes pedagógicos e didáticos”. $\mathrm{O}$ autor nos orienta que, o docente, ante a modernidade e as consequentes inovações, precisa ser capaz em associar à pedagogia, a tecnologia e a boa convivência. Aceitando as diferenças, sejam elas físicas, de qualidade intelectual, de raça, respeitando as suas diferenças e características singulares (religiosas, psicológicas, sociais, ideológicas) de tal forma que isso, não represente uma interferência negativa no processo ensino-aprendizagem.

Outro fator imprescindível ao educador, diz respeito ao domínio do conteúdo a ser ministrado. Também precisa ter a humildade suficiente para assumir que irá pesquisar, quando não tiver a resposta adequada, ante a indagação de algum aluno.

A inovação das aulas precisa ser constante, mas caberá ao professor a orientação e o encaminhamento do conteúdo a ser ministrado. Não pode apenas introduzir a inovação de forma desconexa. É preciso saber fazer uso das ferramentas tecnológicas da forma pedagogicamente correta, incluindo a participação do aluno em aula, para que este não seja apenas passivo, mas participativo. Não basta a aprendizagem ou o reconhecimento de um determinado aplicativo. Faz-se necessário que haja uma teoria que alicerce o conhecimento a ser ministrado, para que o aluno compreenda quando usar e como usar.

Observamos o que nos orienta Freire (1976), "Se o meu compromisso é realmente com o homem concreto, com a causa de sua humanização, de sua libertação, não posso por isso mesmo prescindir da ciência, nem da tecnologia, com as quais me vou instrumentando para melhor lutar por esta causa ( p. 22-23).

Em Resumo, pode-se concluir que é uma ilusão se pensar que o potencial tecnológico existente, seja uma técnica a mais a ser utilizada e, que a mesma irá resolver todos os arestas problemas didático-pedagógicos. Na realidade, a utilização da técnica e/ou do recurso tecnológico, vai depender do contexto, do uso e dos objetivos a serem alcançados.

Uma outra perspectiva é que, por outro lado, como nos coloca Santos et al (2005), não se pode simplesmente desconsiderar o potencial da tecnologia, enquanto produto da sociedade atual. Assim como não se pode desconsiderar o presente, pois a cultura da tecnologia impulsionou mudanças substanciais, e essas mudanças vieram acompanhadas pela característica da irreversibilidade, ou seja, "a instauração e enraizamento das tecnologias da informação e das comunicações, na vida social é um fato consumado" (p. 24). 
Um outro aspecto a se considerar, nos é orientado por Barreto (2003), "Entre as competências do professor, não podem estar apenas novos formatos para os velhos conteúdos, mas novas formalizações" (p. 284).

Esse estudo pretendeu acrescentar conhecimentos sobre o uso das novas tecnologias de comunicação no âmbito universitário, considerando-se as contribuições da literatura especializada. Espera-se que possa abrir campo para a realização de novas iniciativas que o complementem, tendo em vista os poucos artigos abordando a temática, no Brasil. Portanto, o objetivo aqui foi de ser mais um instrumento na compreensão do assunto, não havendo pretensão conclusiva.

\section{Referências}

ASSMANN, H. Reencantar a educação: Rumo a sociedade aprendente. Petrópolis, Rio de Janeiro: Vozes, 1998.

BARRETO, R.G. As tecnologias na formação de professores: o discurso do MEC. Educação \& Pesquisa, n. 30, jul./dez. 2003. p. 271-286.

BRITO, G.S. e PURIFICAÇÃO, I. Educação e novas tecnologias: um repensar. Curitiba: IBPEX, 2006.

FANTIN, M.E. Curso superior de metodologia do ensino da geografia. São Paulo: IBPEP, 2005 .

FREIRE, Paulo. Ação cultural para a liberdade e outros escritos. Rio de janeiro: Paz e terra, 1976.

MASETTO, Marcos Tarciso. Professor universitário: um profissional da educação na atividade docente.IN: Docência na universidade (Org) Campinas, SP: Papirus, 1998.

PERRENOUD, P. Dez Novas Competências para Ensinar, Porto Alegre, Artmed Editora, 2000. 
PIMENTA, Selma Garrido. Docência no ensino superior. São Paulo: Cortez, 2002.

REVISTA VEJA: 19/08/2008 http://veja.abril.com.br/080807/p_102.shtml

SANTOS, Edméa Oliveira dos et al. Competências para docência online: implicações para formação inicial e continuada de professores tutores do FGV online. In: CONGRESSO INTERNACIONAL DE EDUCAÇÃO A DISTÂNCIA, Abed, Florianópolis, dez., 2005. Disponível em: <http://www.abed.org.br/congresso2005/por/ pdf/149tcb4.pdf>. Acesso em: 21 abr. 2007. p. 6.

SANVITO W.L. A comunicação na educação. http://www.oestado.com.br .

\section{Sobre os autores:}

1. Sidney Medeiros de Oliveira.. é graduado em Educação Física pela Universidade Federal de Pernambuco - UFPE. Especializando em Prática Docente do Ensino Superior pela Faculdades Integradas de Patos - FIP. E-mail: sidneymeolli@gmail.com.

2. Weilher Feitosa de Melo é graduado em Licenciatura em Educação Física pela Faculdade Doutor Leão Sampaio e Especializando em Docência do Ensino Superior pela mesma faculdade.

E-mail: weilher_@hotmail.com;

3. Solânia Eugênio Santos Maia é Bacharel em Ciências Econômicas pela Universidade Regional do Cariri; Especialista em Língua Portuguesa, Arte e Educação pela URCA e Especializanda em Metodologia e Docência do Ensino Supeior pela Faculdade do Vale do Jaguaribe - FVJ.

E-mail: jusolsuy@yahoo.com.br

4. Adelmar de Sousa Marinho Neto é acadêmico de Medicina da Universidade Federal do Ceará.

E-mail: aneto@hotmail.com

Como citar este artigo (Formato ISO):

OLIVEIRA, S.M MELO, W.F.; MAIA, S.E.S. e MARINHO NETO, A.S. Uso das novas metodologias de comunicação no ensino superior. Id on Line Revista de Psicologia, Julho de 2012, vol.1, n.17, p.25-34. ISSN 1981-1189. 